\title{
ballot
}

\section{Financiamento público de campanha eleitoral e a negativa ao princípio da maioria}

\author{
Juliana Rodrigues Freitas ${ }^{1}$ (CESUPA, Brasil) \\ rodriguesfreitasjuliana@gmail.com \\ Av. Gov. José Malcher, 1963 - Nazaré \\ 66060230 - Belém, PA - Brasil \\ Patrícia Blagitz ${ }^{2}$ \\ blagitz@uol.com.br
}

\footnotetext{
1. Juliana Rodrigues Freitas. Doutora em Direito Público pela Universidade Federal do Pará/ Università di Pisa - Itália. Mestre em Direitos Humanos pela Universidade Federal do Pará. Pós Graduada em Direito do Estado pela Universidad Carlos III de Madri, Espanha. Professora da Graduação e Mestrado do Centro Universitário do Estado do Pará. Advogada e Consultora Jurídica em Direito Constitucional e Eleitoral.

2. Patrícia Blagitz. Doutora em Direito Constitucional pela PUC-SP. Mestre em Direito Constitucional pela PUC-SP. Professora da Graduação e Mestrado do Centro Universitário do Pará - CESUPA.
} 


\title{
Resumo
}

A proposta de financiamento público exclusivo é um dos pilares da reforma política que tramita perante o Congresso Nacional sob a justificativa que garantirá a observância da igualdade entre os partidos políticos que pleiteiam vagas nas casas legislativas das unidades federativas, assim como impedir a existência de caixa 2 e outras transgressóes não apena à legislação eleitoral, mas, essencialmente, ao Estado Democrático de Direito. Ocorre que o financiamento público exclusivo de campanhas eleitorais não se apresenta, sequer de longe, a melhor saída para a efetivação e observância dos pilares de democracia que sustentam o Estado brasileiro, dentre outros fatores, porque não se propóe a estabelecer um tratamento que torne capaz a legítima disputa eleitoral, de modo a possibilitar a ascensão de partidos políticos com menor representatividade ou nenhuma e, principalmente, por se apresentar como uma negativa ao princípio da maioria visto ser um instrumento de perpetuação das maiorias, nessa condição, impedindo, portanto, o crescimento e o desenvolvimento do debate que deve preceder toda e qualquer produção legislativa.

Palavras-chave: Financiamento público exclusivo. Campanhas Eleitorais. Princípio da Maioria

\begin{abstract}
The exclusive public financing proposal is one of the pillars of political reform which is being processed by the National Congress on the grounds that ensure respect of equality between the political parties which claim places in the chambers of the federal units, as well as prevent the existence of corruption and other transgressions not enough from the electoral law, but ultimately the democratic rule of law. It turns out that the exclusive public financing of election campaigns is not presented, even by far the best solution for the realization and observance of democracy pillars that support the Brazilian State, among other factors, it does not aim to establish a treatment which can legitimate electoral contest, in order to enable the rise of political parties with less or no representation, and especially by present as a negative to the principle of majority, as being a perpetuation instrument of the majority, in this condition, therefore preventing, growth and development of the debate which must precede any legislative production.
\end{abstract}

Keywords: Exclusive public funding. Electoral campaigns. Majority Principle. 


\section{Considerações Iniciais}

A Constituição de 1988 consagrou o pluripartidarismo ao proclamar o pluralismo político como um dos fundamentos da República (artigo $1^{\circ}, \mathrm{V}$ ) e ao prever explicitamente este sistema partidário como valor a ser resguardado quando da livre criação, fusão, incorporação e extinção dos partidos, no artigo 17 , caput.

No sistema pluripartidário há possibilidade de surgimento de inúmeros partidos políticos, com maior ou menor polarização ideológica e com uma multiplicidade de perfis individualizados porque a ordem jurídica, para admitir o pluralismo, garante ampla liberdade de criação, organização, funcionamento e extinção dos partidos. Ao lado disso, o pluripartidarismo é viabilizado através do sistema proporcional que possibilita a representação política com um número restrito de votos.

Todavia, a efetivação de um sistema democrático enfrenta, ainda, alguns entraves estruturais que dificultam a consolidação de partidos fortes e, assim, de um sistema de responsabilização política, uma vez que as instituiçóes políticas estão indissociavelmente vinculadas ao contexto social em que se desenvolvem e atuam. No Brasil, observa Maria Garcia, o excessivo número de agremiações políticas representa uma multiplicidade de interesses localizados, não correspondentes ao aperfeiçoamento da democracia que tem como uma de suas bases o consenso. (GARCIA, 1997)

Scott Maiwaring, em detalhado estudo sobre os sistemas partidários, e, particularmente, sobre o caso brasileiro, demonstra as causas e as consequências de sua baixa institucionalização, propondo o fortalecimento dos partidos uma vez que não há regime democrático sem um sistema partidário pluralista e competitivo. Para o estudo do modelo brasileiro, deve-se observar a capacidade do Estado e das elites políticas em impor, de cima para baixo, os sistemas partidários; isto porque, é pouco institucionalizado o que se caracteriza pela grande instabilidade dos padrões de competição interpartidária, pelo frágil enraizamento dos partidos na sociedade, pelo grau relativamente baixo de legitimidade e pela fraqueza das organizaçóes partidárias. (MAINWARING, 2001)

A instabilidade político-partidária se manifesta, sobretudo, pela facilidade com que os partidos surgem e desaparecem, assim como pela forma como as coligações partidárias, movidas pela simples aposta na vitória eleitoral, demonstram o caráter cosmético da polarização ideológica.

O estabelecimento do direito a recursos do fundo partidário previsto na Constituição (artigo 17, $\S 3^{\circ}$.) e disciplinado pelas Leis 9.096/95 e 9.504/97, é um dos alicerces para a efetividade do pluralismo político e da liberdade de organização partidária. Ante a enorme influência do poder econômico e dos meios de comunicação de massa nos resultados eleitorais, o constituinte estabeleceu o fundo partidário e a propaganda eleitoral gratuita como mecanismos de equilíbrio da disputa eleitoral, porém, não é o que ocorre, considerando o modelo misto, vigente atualmente. E, tampouco ocorrerá, com a implantação da proposta de financiamento público exclusivo de campanha eleitoral.

A liberdade de organização e funcionamento dos partidos implica a existência de recursos financeiros, mais vultosos à medida que aumenta a complexidade organizativa dos partidos e a sofisticação da propaganda eleitoral. Assim, os partidos necessitam de condições financeiras para manter seu funcionamento ordinário - v.g. manutenção de sedes, cursos, seminários - e para dar cabo a campanhas eleitorais eficientes, do ponto de vista do convencimento do eleitorado. 
Os partidos políticos devem desenvolver uma atividade política contínua, desempenhando funções de informação, educação e articulação da multiplicidade que possibilita a democracia. Veiculam interesses de diversos setores sociais e, por isso, a ajuda pública dirigida ao seu funcionamento ordinário e manutenção de sua organização se legitimam constitucionalmente em um Estado Social de Direito. (GONZÁLES, 2002)

A previsão do direito de participação dos partidos nos recursos do fundo partidário pela Constituição demonstra a preocupação constituinte com dois aspectos fundamentais do processo eleitoral: o interesse público na manifestação da vontade popular e a instituição de mecanismos de igualização de oportunidades na organização partidária e nas campanhas eleitorais. De um lado,"a transcendência do processo de formação e manifestação da vontade popular justifica que o Estado assuma parte do custo econômico gerado por dito processo." ${ }^{3} \mathrm{De}$ outro, ao pluralismo político deve corresponder a efetiva possibilidade, portanto viabilidade financeira, de expressão das diversas correntes políticas com igualdade de oportunidades. (LENERA, 1999, p. 217)

O sistema de financiamento das campanhas guarda relação com o sistema partidário adotado e, sobremodo, com o modelo econômico de Estado. Assim, a doutrina aponta três modelos básicos de financiamento: nos Estados totalitários os partidos funcionam como agentes do governo o que implica o financiamento estatal; no modelo liberal, os partidos são concebidos como agentes apenas da sociedade, gerando o financiamento exclusivamente privado; e o pensamento político moderno concebe os partidos como agentes duais, é dizer, representam a sociedade e desempenham um papel primordial na conformação do poder político do Estado e, portanto, os dois devem contribuir ao seu financiamento, surgindo, desta concepção a ideia do financiamento misto. (TORRES, 1998)

Uma das finalidades primordiais do financiamento das campanhas nos diversos países é garantir a igualdade de oportunidades, evitando-se o abuso de poder econômico. Para tanto, o Estado adota medidas positivas e negativas a fim de fazer efetiva a igualdade de oportunidades dos partidos, tais como: através do financiamento da atividade de campanha dos partidos e das limitaçóes quanto aos gastos eleitorais, de modo os partidos economicamente fortes não coloquem os demais em qualquer posição de desvantagem, a de proibir a publicidade televisiva nas antenas privadas e por último, a de restringir as contribuiçóes privadas, por exemplo.

No direito brasileiro não há determinação constitucional expressa quanto ao caráter integral ou parcial do financiamento dos partidos e das campanhas, cabendo as normas infraconstitucionais regerem o financiamento parcial da atividade partidária, com limites relativos. O limite absoluto diz respeito ao recebimento de contribuições provenientes de entidade ou governo estrangeiro, por expressa disposição constitucional repetida, desnecessariamente, na Lei 9.096/95.

3. Também Maria Holgado Gonzáles explica que a Espanha se alinha entre os países europeus que, de maneira generalizada a partir do segundo pós-guerra, assumem uma parte importante do financiamento dos partidos políticos, de forma coerente com o reconhecimento constitucional do papel desempenhado por estes no funcionamento do sistema democrático, ao concorrer à formação da vontade política do povo. GONZÁLES, Maria Holgado. Op. cit. p. 133. 


\section{Princípio da maioria e a representatividade legislativa}

Fundamental perceber que a discussão em torno do financiamento das campanhas eleitorais está diretamente relacionada à composição das Casas Legislativas, principalmente, no que toca à alternância dos cargos, e consequentemente, da representatividade dos grupos majoritários e minoritários.

É essencial para o processo democrático que a maioria ordinária não seja estanque e se perpetue nessa condição; isto é, a representatividade do grupo majoritário deve também sofrer alternância para que as minorias se tornem maioria, e vice versa, numa permissão que deve ser garantida pelo processo eleitoral - inclusive com um sistema de financiamento que seja justo -, e autorizada pelos cidadãos que elegem deliberadamente, porém, com consciência coletiva, os seus representantes.

De acordo com o entendimento muito bem exposto por Vital Moreira, a vontade política da maioria governante de cada momento não pode prevalecer contra a vontade da maioria constituinte incorporada na lei fundamental, pois a limitação da vontade da maioria ordinária decorre da supremacia de uma maioria mais forte. (MOREIRA, 1995, p. 177/198).

Assim, as leis, produto da atuação da maioria ordinária, são presumidas compatíveis aos limites impostos pela maioria constituinte pelo fato de terem sido elaboradas por integrantes do órgão representativo dos vários setores sociais que, através de um procedimento democrático, questionaram diversos interesses e direitos coletivos, tais como: o direito à vida, à liberdade de expressão, ao sufrágio e à educação.

Esse processo democrático apresenta, em tese, mais legitimidade para criar decisóes corretas sob o ponto de vista moral do que qualquer outro tipo de procedimento, em razão da participação dos que serão destinatários do seu resultado, durante a deliberação coletiva e tomada de decisóes.

Em tese, porque se os partidos com menor expressão política não tiverem as mesmas condições de alçar uma vaga nessa representatividade (e para isso, critérios observando a maior e menor representatividade dos partidos políticos, devem ser criados para permitir o acesso a essas vagas indistintamente por todos), essas decisões não poderão ser consideradas as mais legítimas sob o plano da moralidade, visto que nem todos os destinatários serão ouvidos, em especial aqueles integrantes dos grupos representados pelos partidos políticos de menor projeção.

A partir da discussão estabelecida entre os vários setores sociais representados politicamente e, finda esta, com a decisão emanada por todos, poder-se-á conhecer a verdade que integra o seio social, a verdade moral, possibilitando esse processo deliberativo que toda e qualquer decisão, porventura adotada pelos poderes públicos, esteja calcada em bases consideradas relevantes, não apenas para a sociedade, mas, principalmente, pela própria sociedade, tornando-se, assim, de mais fácil conhecimento os direitos e as liberdades que fundamentam, com mais legitimidade, os valores da justiça e moralidade, motivadores da criação da ciência jurídica.

Embora esse procedimento democrático não garanta que as decisões adotadas sejam sempre justas, posto que o órgão parlamentar no momento da discussão e aprovação do conteúdo normativo poderá preterí-lo em prol da vontade de uma facção política; é, no entanto, o que melhor proporciona o alcance da justiça na adoção dessas normas, pois dele participam, através de sua voz e voto, os representantes das pessoas sobre as quais incidirão os resultados políticos.

É o que de acordo com a teoria de John Rawls abordada por Comella, se define como uma justiça processual imperfeita, vez que não está garantida a justiça nas decisões legislativas, mas, 
ainda que apresente falhas, tende a proporcionar decisóes mais corretas do que qualquer outro procedimento alternativo, justamente porque se perfaz a partir da participação dos interessados, ainda que através dos seus representantes, na tomada de decisões. (COMELLA, 1997, p. 164)

Além da participação dos interessados na definição dos valores que fundamentarão as normas elaboradas, deve ser aplicada a regra da maioria nesse processo deliberativo, de acordo com a qual todas as heterogeneidades fomentadas serão discutidas e destas serão extraídas as soluçóes capazes de melhor coadunar o querer da minoria aos da maioria, sem que isso implique, num necessário convencimento do grupo minoritário de que a decisão adotada lhe tenha sido a mais benéfica, mas, sim, que foi capaz de melhor harmonizar ambos os interesses, evitando, nesse contexto, minimizando os eventuais prejuízos e conflitos intrasociais.

Porém, para que todas as heterogeneidades se façam presentes nesse processo democrático é necessário que a escolha dos representantes e partidos políticos ocorra com a menor influência possível de fatores como o econômico, e de outra sorte, seja a expressão de uma discricionariedade consciente dos cidadãos.

Dialogando com o renomado jurista argentino Carlos Santiago Nino, Comella discute que para que o procedimento democrático represente o ideal de um processo deliberativo, sendo revestido de perfeição, necessário seria que a discussão estabelecida entre os atores sociais culminasse com a unânime aceitação da decisão tomada, pois quanto maior o número de pessoas apoiando tal decisão, maior a probabilidade de a mesma corresponder a todos os interesses sociais em questão; mas, como não se torna sensato discutir, indefinidamente, sobre o que deve ou não ser normatizado, até que se alcance a hegemonia das decisóes, deve-se priorizar a regra da maioria.

Existe uma situação fática passível de mudança, denominada status quo, a qual não pode preponderar sobre a necessidade de inovaçóes normativas, regulamentadoras das modificaçóes sociais, sentidas em razão do constante aprimoramento do pensamento e do querer humano.

Diante desse contexto, não se pode permitir que a minoria que prefere manter o status quo, não desejando mudanças, prevaleça sobre o querer da maioria ávida por transformações e desenvolvimento. Justifica-se, portanto, a não exigência da unanimidade - que é de difícil alcance - para a aprovação de um novo texto jurídico, sendo suficiente a aprovação majoritária.

Problema a essa teoria surge quando a minoria é que está ávida por mudanças e se propõe a discutir ações de planejamento e desenvolvimento sociais e não consegue aprová-las porque sempre continuará nessa condição, de minoria, tendo em vista o sistema de acesso aos cargos políticos proposto, dentre outros fatores, pelo modelo de financiamento de campanha eleitoral definido em lei pela própria maioria?!

Então, não podemos afirmar que as decisóes da maioria, diante desse contexto, continuam sendo amparadas pela legitimidade democrática, corroborando-se, ao contrário, como fonte de esgotamento e perpetuação no poder e nas deliberações de um status quo contrário aos ideais da democracia.

Cass Sustein elege de forma muito clara em sua obra a deliberação política como uma das características do processo democrático, ao admitir que os resultados políticos, como os textos normativos, não devem ser fruto de uma regulamentação de interesses próprios de grupos privados bem organizados ou uma proteção formal de direito, através da simples codificação de preferências existentes. (SUSTEIN, 2000, p.133/135)

Para que esses diplomas legais sejam elaborados, é preciso que seja respeitado um procedimento específico, que se iniciará com o processo de deliberação, durante o qual serão 
consultados e discutidos os interesses passíveis de regulamentação, que sofrem frequentes mutações naturais de qualquer grupo social.

A regra da maioria não pode ser concebida como uma simples mudança de status quo, visto que para que toda e qualquer transformação social seja objeto da ciência jurídica, através da sua normatização, é preciso que lhe seja precedido o método da discussão, consulta e persuasão, no qual não apenas se priorizarão os direitos a serem positivados, como também, a minoria que não teve os seus interesses satisfeitos será ouvida e instigada, por meio da persuasão exercida pela maioria, a conciliar os seus objetivos aos que foram positivados.

Não basta apenas implementar modificaçóes com o apoio de um grupo, por mais que este seja o mais expressivo socialmente; é preciso, ademais, que tais transformações sejam justificadas como o melhor instrumento de alcance e satisfação das necessidades sociais.

Observe-se que essa discordância e heterogeneidade são estímulos para a criação das mais diversas soluçóes capazes de satisfazer os distintos interesses que surgem numa sociedade, promovendo, assim, o próprio desenvolvimento desse grupo social, pois serão priorizados os resultados que melhor harmonizem essa diversidade de aspirações.

De acordo com a visão de Sustein, para que seja analisada a deliberação política como forma de expressão da democracia, é preciso que se tenha em vista durante todo o procedimento de tomada de decisões legislativas, outras três vertentes: o exercício da cidadania, a necessidade de se coadunar o querer dos cidadãos através de um acordo e a igualdade política.

O conceito de cidadania não deve se limitar ao da escolha de representantes capazes de defender os interesses sociais, mas ser tida como um instrumento, do qual se vale a sociedade para cobrar açóes governamentais destinadas ao suprimento dos anseios sociais. Para tanto, é imprescindível que seja mantida uma relação de independência da sociedade para com o Estado, justamente para que esse instrumento de cobrança não se torne inócuo.

As formas de expressão dessa imunidade social contra as possíveis arbitrariedades estatais se assentam na defesa da propriedade privada, bem como, todos os direitos essenciais a uma vida digna, como: saúde, educação, liberdade de expressão, dentre outros.

O segundo aspecto que deve integrar o processo de deliberação política para que o mesmo se norteie de acordo com os fundamentos democráticos é a necessidade de se firmar um acordo entre os cidadãos, pelo qual serão encontradas respostas corretas para as controvérsias políticas; ou seja, respostas que se revistam de legitimidade por expressarem o querer social, e, para isso se faz imprescindível a deliberação a fim de que se alcance o ponto comum que represente a todos.

A democracia deliberativa também é caracterizada pelo ideal de igualdade política, de acordo com o qual se faz necessária a eliminação de largas disparidades entre as influências políticas exercidas pelos diversos grupos sociais. Entretanto, para que exista uma relativa homogeneidade na politização dos homens que compõem um corpo social, torna-se essencial que se promova o acesso à educação, posto que somente o conhecimento gera a possibilidade de se questionar conscientemente, seja para defender que rejeitar, uma tomada de decisão.

Para a igualdade política ser alcançada é preciso, inicialmente, que sejam supridas as necessidades humanas vitais, como: proteção policial, comida, moradia e cuidados médicos adequados, para a garantia da condição de cidadão e da dignidade dos homens, conforme declara Sustein: "a modest minimum of food, medical care, and shelter is necessary for people who hope to obtain the status of citizens. People without these advantages cannot attain that role at all". (SUSTEIN, 2000, p.138) 
Além da proteção dessas mínimas condições para a vida humana, a igualdade política implica na rejeição ao sistema de castas, pelo qual são priorizados os interesses de um grupo minoritário, já titular de uma série de regalias, em detrimentos aos da maioria desfavorecida. Esse sistema no qual são beneficiados pequenos grupos com significativa imponência econômica, que, em razão disso, se prevalecem politicamente, não se coaduna à democracia deliberativa, contrapondo-se aos princípios da cidadania e igualdade política.

E, por fim, implica a igualdade política na minimização das diferenças de oportunidades, pois, ainda que se admita a impossibilidade da igualdade real entre todos, as diferenças humanas são produto também das diferenças de oportunidades, as quais podem ser atenuadas pelas ações governamentais.

Corroborando tal entendimento de Sustein, para que a igualdade política se torne realidade é essencial que o Estado proporcione igualdade de oportunidades também em relação àqueles que querem exercer o direito de representar a sociedade, através da capacidade eleitoral passiva. Para que isso ocorra, torna-se imprescindível a regulamentação de um processo eleitoral que permita a alternância efetiva nos cargos eletivos, partindo, dentre outros pontos, da previsão de um financiamento de campanha coerente com a nossa realidade política, o que não ocorrerá se o atual modelo de financiamento público exclusivo posto em discussão for aprovado.

No campo político-eleitoral, a igualdade impóe a promoção do relativismo inerente à democracia: as diversas concepções políticas devem ser igualmente respeitadas, com iguais possibilidades de divulgação e concorrência. Portanto, os partidos devem ter assegurada a igualdade de oportunidades para ocuparem os cargos políticos no Estado. Como observa José Joaquim Gomes Canotilho,

uma 'igualdade esquemática' excluirá, desde logo, qualquer discriminação jurídica entre 'partidos grandes' e 'pequenos', 'partidos de governo' e 'partidos de oposição', partidos com 'representação parlamentar' e 'partidos sem representação parlamentar'. Adianta-se também que os partidos do governo não podem extrair quaisquer 'mais-valias' da 'posse legal do poder'. (CANOTILHO, 1998, p.305)

A igualdade política conduz ao relativismo inerente ao ideal democrático porque possibilita a cada cidadão a mesma possibilidade de participação, a mesma possibilidade de expor suas opinióes e buscar o convencimento de outros cidadãos. Porém, é necessário lembrar que a ideia de democracia não se resume à prevalência absoluta da vontade da maioria, constatada pela expressão da vontade popular das últimas eleições. Como o regime democrático pressupõe livre oposição e espaço para o debate público, atribuir mais recursos e espaço para os partidos que já ocupam maior parcela do poder político no Estado significa criar um sistema de retroalimentação do poder das agremiações consolidadas, com o comprometimento do pluralismo e das alternativas políticas.

O Projeto de Lei no Senado (PLS) n. 268/2011, foi publicado no Diário do Senado Federal no dia 19 de maio de 2011, como conclusão dos trabalhos da Comissão de Reforma Política do Senado Federal, de autoria dos Senadores José Sarney e Francisco Dornelles, propondo o financiamento público exclusivo das campanhas eleitorais, e, de imediato, vinculando-o à adoção do sistema de lista fechada para a composição das casas legislativas nas quatro esferas das unidades federativas do Estado brasileiro. 
Sob o fundamento de que a proposta de financiamento público exclusivo das campanhas eleitorais inspira-se na necessidade de redução dos seus gastos, que crescem exponencialmente, bem como para por fim à utilização de recursos não contabilizados, oriundos do chamado "caixa 2". Para além disso, permitirá, segundo os argumentos trazidos no texto do projeto, a possibilidade de se verificar se a prestação de contas dos partidos políticos e candidatos está compatível com os gastos realizados pelos mesmos.

Faz-se, ainda, referência ao princípio da igualdade, no sentido de que um dos objetivos que os regimes democráticos têm buscado em matéria de eleiçóes é o do tratamento igualitário dos concorrentes ao pleito, de forma a impedir que alguns alcancem a vitória eleitoral, não pelo convencimento das teses e do programa que propõem, mas em função da arregimentação e da pletora de propaganda eleitoral propiciadas pelo seu poder econômico.

O que se observa, entretanto, é que os argumentos desenvolvidos para a adoção do financiamento público exclusivo são extremamente frágeis e ineficazes para justificar esse modelo.

A prestação de contas de campanha pode e deve ser observada se houver também limite para a doação por parte de particulares, por exemplo, e a existência de caixa 2 não se limita aos sistemas que adotam o financiamento privado ou misto, infelizmente, podendo existir, da mesma forma, nos processos eleitorais financiados pelos cofres públicos.

Desde que não haja efetiva fiscalização e punição aos infratores da legislação que regulamenta a matéria eleitoral, e, acima de tudo, enquanto não houver consciência política de que o voto não deve ser comprado ou eleitor induzido a votar em tal ou qual candidato em razão do poderio econômico do qual aparenta ser titular, mas sim, que deve existir uma conquista razoável ao ponto de justificar nos valores democráticos e no princípio da representatividade política e definição dos candidatos eleitos.

\section{Conclusão}

A democracia, fundada na soberania popular, impóe que a vontade geral esteja o mais próxima possível da vontade de todos. Como a liberdade-participação deve ser assegurada a todos indistintamente, as decisões políticas fundamentais devem ser tomadas com base na concordância do maior número possível de cidadãos.

O regime democrático é, por essência, contrário à imposição de vontades minoritárias, quaisquer que sejam elas. Entretanto, o princípio da maioria, por imposição lógica, pressupõe a existência de uma minoria.

Quando se refere ao reconhecimento de direitos e liberdades fundamentais à minoria, deve se entender a dialética democrática não como um sistema bilateral, mas como um conjunto de correntes cuja situação de minoria ou maioria pode ser cambiante, no sentido de alternância no poder, ou de ascensão da minoria à qualidade de maioria. Por isso, para que o sistema político não seja engessado pelo continuísmo de grupos no poder, os direitos fundamentais assegurados às minorias não se limitam apenas à participação formal no processo político, mas a direitos que assegurem uma efetiva democracia de minorias competitivas, através de instrumentos como a ampla liberdade de criação dos partidos, a garantia de seu acesso aos meios de informação política e recursos financeiros que assegurem efetiva igualdade de chances.

\section{ballot Rio de Janeiro, V. 1 N. 1, Maio/Agosto 2015, pp. 249-260}


Ocorre que o que se observa é que esse modelo de financiamento público exclusivo de campanha eleitoral apenas reforça a violação ao princípio da igualdade já existente e tão manifesta no processo eleitoral, além de representar uma afronta ao princípio da maioria, principalmente no que tange ao aspecto da alternância política e na possibilidade da minoria vir a se tornar maioria num debate político.

Reforça porque não se propõe, dentre outros motivos, a estabelecer um tratamento que permita o concurso ao processo eleitoral de forma isonômica entre os partidos maiores e menores.

Sim, porque a necessidade de se reconhecer a existência das minorias durante o processo de deliberação política ocorre também em razão do fato de, no futuro, o grupo que hoje assim se apresenta poder vir a se transformar numa expressão da maioria da sociedade. E como isso poderá ocorrer se a proposta de financiamento público exclusivo de campanhas eleitorais impede essa alternância na representatividade, autorizando a perene hegemonia e força dos partidos políticos de maior envergadura em contraponto com a constante inacessibilidade dos grupos minoritários nos processos deliberatórios e decisórios democráticos, não porque não se fazem ouvir, mas porque, são os partidos políticos com menor representatividade que, de fato, traduzem os seus interesses.

Se não existe essa alternância política, a expectativa de que a minoria se torne, um dia maioria, jamais será atendida, e, portanto, não podemos vislumbrar a democracia num das suas facetas mais genuínas, pela simples frustração dessa expectativa de alternância política, e, portanto, de representatividade.

O projeto de financiamento público exclusivo de campanha eleitoral, portanto, ao distribuir em percentuais ou valores iguais o dinheiro que é do povo para perpetuar a preponderância dos grandes facçóes em detrimento das menores, para além de violar o princípio da igualdade, porque não permite que os partidos políticos tenham a mesma oportunidade de eleger seus candidatos e, muito menos, na mesma proporção; representa uma afronta à democracia, consubstanciada, nesse caso, pela transgressão ao princípio da maioria, um de seus pilares.

\section{Referências Bibliográficas}

CANOTILHO, José Joaquim Gomes. Direito constitucional e teoria da constituição. 2a ${ }^{\mathrm{a}}$ ed. Coimbra: Almedina, 1998.

COMELLA, Víctor Ferreres. Justicia Constitucional y Democracia. Madri: Centro de Estudios Políticos y Constitucionales, 1997.

GARCIA, Maria. A democracia e o modelo representativo. In: GARCIA, Maria (coord.) Democracia, hoje. Um modelo político para o Brasil. São Paulo: Instituto Brasileiro de Direito Constitucional, 1997.

GONZÁLES, Maria Holgado. Financiación de partidos y democracia paritaria. Revista de Estudios Políticos. Nueva Época, n. 115, jan./mar. Madri: Centro de Estudios Políticos y Constitucionales, 2002. 
LENERA, Miguel Ángel Presno. La reforma del sistema de financiación de los partidos politicos. Revista Española de Derecho Constitucional. n. 57, set./dez., ano 19, n. 57, set./dez. Madri: Centro de Estudios Políticos y Constitucionales, 1999.

MAINWARING, Scott P. Sistemas partidários em novas democracias: o caso do Brasil. Trad. Vera Pereira. Porto Alegre- Rio de Janeiro: Mercado Aberto-FGV, 2001.

MOREIRA, Vital. Princípio da maioria e princípio da constitucionalidade: legitimidade e limites da justiça constitucional. In: Legitimidade e Legitimação da Justiça Constitucional. Lisboa: Coimbra Editora, 1995.

SUSTEIN, Cass R. The Partial Constitution. Cambridge, Massachusetts, and London, England: Harvard University Press. 2000.

TORRES, Carlos Ariel Sánchez, La financiación de los partidos politicos y las campañas electorales. El caso colombiano. Revista de Derecho Público. N. 9. Bogotá: Universidad de los Andes, 1998. 
Recebido em: $11 / 05 / 2015$

Aceito em: 25/05/2015

\section{Como citar}

FREITAS, Juliana Rodrigues; BLAGITZ Patrícia. Financiamento público de campanha eleitoral e a negativa ao princípio da maioria. Ballot. Rio de Janeiro: UERJ. Volume 1 Número 1 Junho 2015. pp. 249-260. Disponível em: [http://www.e-publicacoes.uerj.br/index.php/ballot]

\section{(C) $\oplus \Theta \odot$}

A Revista Ballot está licenciada sob uma licença Creative Commons Atribuição - Não Comercial - Compartilha Igual 3.0 Não Adaptada. 